\title{
THE RELATIONSHIPS BETWEEN STUDENTS' SELF-CONFIDENCE AND THEIR ENGLISH-SPEAKING PERFORMANCE: A CASE STUDY OF ENGLISH-MAJORED STUDENTS AT A PRIVATE UNIVERSITY IN VIETNAM
}

\author{
Anh Tuan Phami, \\ Hieu Trung Hong, \\ Tien Thuy Chau, \\ Nhi Vo Anh Le, \\ Phuc Thuy Thy Tran, \\ My Ngoc Nhat Nguyen \\ FPT University, \\ Vietnam
}

\begin{abstract}
:
This research aimed to discover the relationships between students' self-confidence and their English-speaking performance. In our research, self-confidence was divided into three components which are affective confidence, behavioral confidence, and cognitive confidence. In addition, speaking performance included eight components which are vocabulary, grammar, pronunciation, fluency, coherence, comprehension, task, and content. A sample of 150 English-majored students at a university in Vietnam was surveyed in this study by using a convenience sampling technique, and then conducting semi-structured interviews to seek for qualitative information from 10 participants out of 150. The result from our study showed that there are significant relationships between the two variables. The more confident the students are, the more accomplished they would be in the presenting procedure since they have superior cognition and understand how to modify their learning methods to build a comprehensive individual in learning English language. We expect that these findings can help students adjust their learning methods to improve their self-confidence as well as English speaking performance and by that way, universities can add more speaking-related subjects so that students can have more opportunities to speak and learn more speaking skills.
\end{abstract}

Keywords: self-confidence, speaking skills, relationships, performance

i Correspondence: email anhpt66@fe.edu.vn 


\section{Introduction}

For foreign language learners, especially, English language learners, speaking is one of the most crucial aspects of English proficiency to acquire. This suggests that learning a foreign language and being able to speak are two distinct things as we must deal with contextual language. It is possible to determine that this competence can be learned and mastered as a means of efficient communication (Morozova, 2013).

Meanwhile, self-confidence in the field of foreign language speaking performance has multi-dimensional impacts and is influenced by multi-factor, which is an essential component that is mostly investigated in different contexts. Studies related to the determinants of self-confidence to students' capabilities to be fluent in their English language (mostly were about English that was learned as second language - L2 or foreign language - EFL) examined the correlation between those determinants and students' speaking performance in terms of their speech's results. Those results would be reflected by the students' scores (Park \& Lee, 2005), lecturers' comments (Arifin, 2017), or their self-reflection (Nadiah, 2019, Tuan \& Mai, 2015). The last point was at a higher frequency of self-confidence research as that from those mindsets, researchers gathered them up together to draw inferences about determinants of students' self-confidence serving as anxiety, inhibition, or self-esteem. However, wider fields of self-confidence determinants had not yet been studied thoroughly, which related to a person's affective, behavioral and cognitive influenced factors (abbreviating to ABC) (Schohn \& Shrauger, 1995).

Driven to the examination, we hope to make contributions to further research in the significance of self-confidence and psychological determinants towards language learners (both for L2 and FL learners) in a Vietnamese context. We identified that the students' English proficiency has been mainly focused on receptive skills such as reading and listening, whereas their capability to speak needs to be strengthened more thoroughly. Since they have less opportunities to practice speaking, it is a struggle for them to make their speech fluent, while speaking is an essential skill each student must possess when studying at universities or higher education. From voicing opinions in lessons, making class presentations, or the final speaking test, students' performance has been marked poor and unsuccessful. It can be assumed that students' ability to reach a higher level of self-confidence is still vague and frustrating.

As we emphasize, the key influential factors are self-confidence and students' psychological operation, factors related to students' English proficiency will be examined as mainstream influential factors in later research. This current study contributes significantly to the educational environment, especially for speaking performance of English language learners in terms of psychological and behavioral factors. Since they are difficult to modify, this study is helpful in benefiting students to enhance their confidence in speaking English, that they will be more engaged in adapting their learning methods, strengthening their self-confidence and their language speaking performance. Furthermore, it is expected to help educational institutions and teachers/ lecturers in 
assisting their students to speak English more confidently. Specifically, this study explores the following research questions below:

1) Are students' self-confidence and their English-speaking performance related?

2) What are the relationships between students' self-confidence and their Englishspeaking performance?

\section{Literature review}

\subsection{Definition of self-confidence}

As one of the fields that is studied with the concept of the self, self-confidence can be conceptualized into multiple dimensions. Most of the time, the term "cognitive" is used to describe self-confidence as it is somehow a mental related issue. Self-confidence, according to former researchers, is defined as an individual's skills and abilities, which they use to effectively improvise in a particular situation (Berger, 1992; Andrew \& Itsiopoulos, 2016; Axelrod, 2017; Shrauger \& Schohn, 1995). More specifically, selfconfidence is the level to which an individual is self-aware of his or her abilities, which means they self-assess what they can and cannot do, thereby determining their behaviors (Oney \& Oksuzoglu Guven, 2015).

Other definitions provided self-confidence as being established through integrating multiple judgment and convincing processes in which individuals ascribe significance towards their own experiences about failures in past performancesperspectives of how others react to them (Axelrod, 2017). It is transmissible, inspires, persuades, and encourages others. Individuals will be able to obtain self-confidence if they are able to deal with anxieties (Hill, 1928).

\subsection{Classification of self-confidence}

It was believed that confidence is segmented into three categories which are affective confidence, behavioral confidence, and cognitive confidence (Shrauger \& Schohn, 1995). Built on other previous studies' foundation of attitude, Ostrom (1969) has formed an ABC Model, of which presents a relationship between the acknowledgement of three components of attitude, which are affective (A), behavioral (B) and cognitive (C) components. His experiments concluded that whenever examining the causal relationship between a certain object with the model, it is better to test each type of component with its agnate type of the object as a component has higher correlation with itself than with other components. Acknowledging this point, we conceived his conclusion as the base of our study in clarifying the relationships between the two determined variables.

According to Erin Long-Crowell in The ABC Model of Attitudes (2013), affective component describes an individual's emotional reaction to an attitude object. It is the outward manifestation of one's inner world and attitude toward a particular thing, circumstance, or experience. Eagly \& Chaiken (1998) claimed that in the context of 
attitudes, affect has been described in the context of attitudes as the emotions, feelings, and sympathetic nervous system activity that people have had regarding an object of attitude and have come to associate with it. Krashen (2003) pointed out that the affective factor is one of the most important factors that influence the process and outcome of Second Language Acquisition (SLA). Krashen's theory of SLA hypothesized that the affective filter is a psychological obstacle that makes language learners unable to comprehend available comprehensible input fully. Affective factors include certain emotions, such as motivation, self-confidence, anxiety. He believed that all three factors determine the output in the process of language learning. Meanwhile, Arnold (1999) stated that affective components composed of motivation, attitudes, and feelings also affect the process of trying new language learning. Attitude factors and feelings factors are two big categories, including both self-confidence factors and anxiety factors inside. Thus, the two authors, Krashen (2003) and Arnold (1999), had a similarity in identifying the three factors included in the affective component, which affect the outcome of the language learning process.

The second component is behavioral. Behaviorism is the psychology of observed behavior. The behaviors that are observed, recorded, and measured are the ones that matter in human or animal research. In other words, behavior refers to what one organism acts, or more especially, what another organism observes (Watson, 1998; Skinner, 2019). The fraction of an organism's activity that engages in activities with the outside world is called behavior. According to Skinner (1957) and Watson (1998), any factor that affects an organism is defined as stimulus, and the behavior which the organism answers back to that stimulus is called a response. Stimuli come from the outside world, and also come from inside our body as well. Moreover, the response that is visible is called an external (or overt/explicit) response, while the response that occurs inside an organism (not visible) is called an internal (or explicit) response, and the same to the stimulus. Johnson (2004) developed that organisms are always adjusting their behavior to new environments or circumstances that occur around them, and so are language learners. Thus, behaviorism asserts that the environment is the source of learning and growth. Skinner (1957) stated that the learning development of organisms is through responding to stimuli and reinforcing them until it becomes a habit. In contrast, Chomsky (2013) argued that behavior, including language learning, is based on organisms' intrinsic cognition rather than behavioral reinforcement.

The last component of self-confidence is cognitive, which was previously therefore considered in any field of research as long as it is human-related. A taxonomy was developed by Bloom et al. (1956) presenting processes of cognition from the basement to the ultimate usage of knowledge. In this study, we examine the revised version of the taxonomy, including remember, understand, apply, analyze, evaluate, and create, by Anderson et al. (2001). It is underscored that in the knowledge acquisition process, language learners should step through those six levels of cognitive development from observing an object, accepting it in their memory, analyzing its components and 
emerging it into their existing knowledge for future application (Bloom et al., 1956; Piaget, 1952; Bandura, 1986).

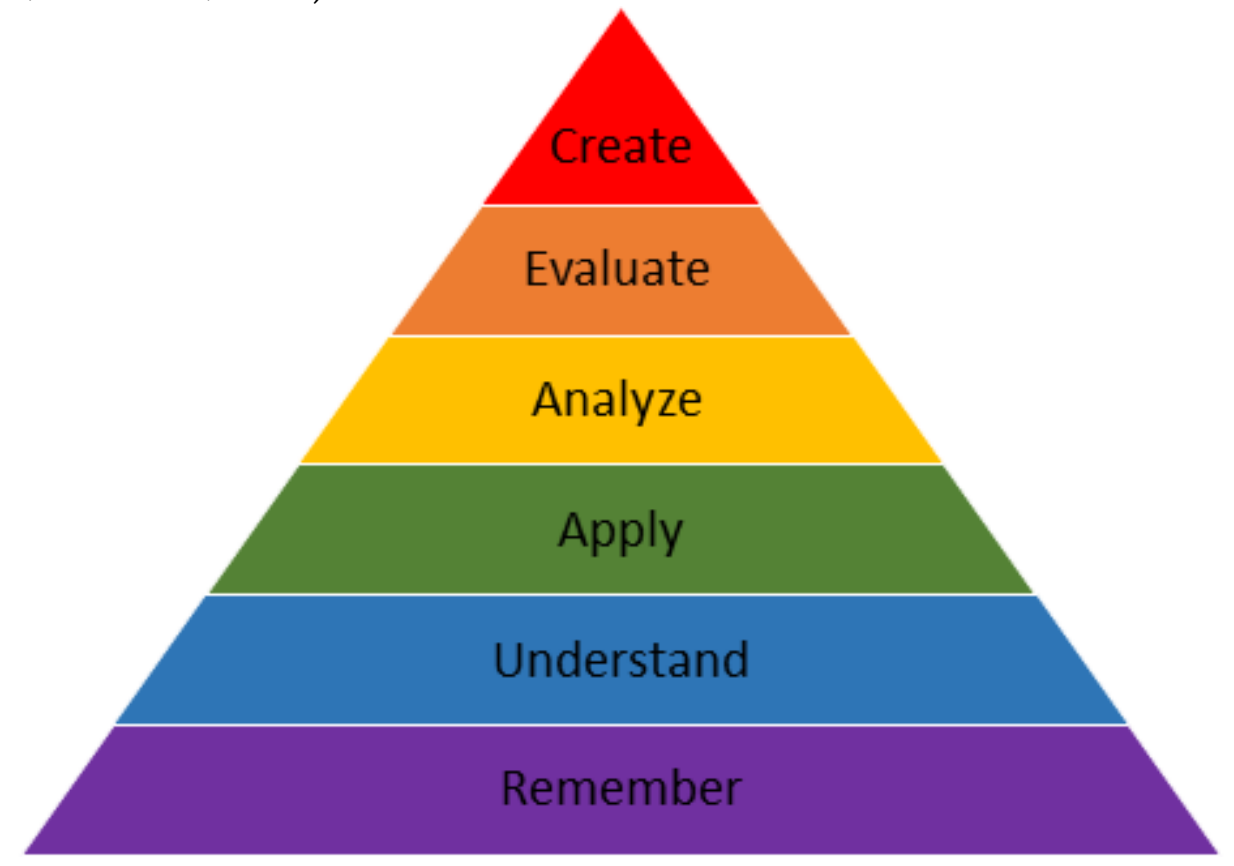

Figure 1: The revised Bloom's taxonomy by Anderson et al. (2001)

Working on the Social Cognitive Theory (SCT), Bandura (1986) has argued that learning through observations, modelling and imitations from others is not enough, learners must include cognition processes into their study, which is an important determinant for their knowledge-structuring process. His structure of four sub processes of cognitive development (attention, retention, production, and motivation) were partly developed along the same lines with Bloom's taxonomy (Bandura, 2001; McLeod, 2016). Sharing similar characteristics with the SCT, Piaget's Theory of Cognitive Development (1952) has also highlighted the importance of social factors affecting one's cognition by providing four stages of cognitive development, which were sensorimotor, preoperational, concrete operational, and formal operational stages (Piaget, 1952; McLeod, 2018). His argument of people's logics were practice-needed abilities met Bloom's ideas of cognitive development as they both demonstrated the necessary processes to employ knowledge. All of the three theoretical constructions are essential, which means the upper level could not happen if learners did not possess the lower level. Nevertheless, while Bloom has stressed the intrinsic motivations that affect learners' process of development, Bandura spent more analysis on environmental factors since he determined society is the human source of learning. He argued that people's cognition is driven by the environment and has a causal relationship with the social systems (Bandura, 2001, p.266). Criticisms related to Piaget's cognitive development stages due to its incompleteness as it stopped at the formal operational stage have risen, which is in this study, Bloom's taxonomy is more appropriate employing into the university context of research than others. 


\subsection{English-speaking performance}

Speaking is the ability to pronounce articulation of sounds or words for expressing, stating and delivering thoughts, ideas and feelings. Meanwhile Brown (2004) stated that speaking is an effective skill that can be directly and experimentally observed. According to Harris (1974: 68-69), "Speaking is a complex skill that requires the simultaneous use of different abilities that often develop at different rates." Therefore, it can be concluded that speaking is an ability to communicate orally to other people with the aim to express their ideas and feelings.

Brown (2004) has stated six components of speaking to be scored; pronunciation, grammar, vocabulary, fluency, comprehension and task. Harris (1974) suggested that speaking skill has five components: comprehension, grammar, vocabulary, pronunciation and fluency. Tuan (2012) said that depending on the assessment purpose, speaking effectiveness can be evaluated based on content, organization, coherence, registration, vocabulary, and grammar. Despite dividing speaking skills into components with different names, all of the studies gave similar results. From the study of Harris (1974), Brown (2004) and Tuan (2012), we can point out that eight components of speaking are very crucial, including pronunciation, grammar, vocabulary, fluency, comprehension, task, coherence and content. Students can use these components to improve their speaking skills, thereby improving their speaking performance.

\subsection{The relationships between self-confidence and English-speaking performance}

To have a fluent and successful speech in any situation, one must perceive a certain selfconfidence level. It is possible to demonstrate the relationships between one's selfconfidence and his/her speaking performance. From what was examined, a number of previous researchers have agreed that there are significant relationships between students' self-confidence and their speaking performance, especially in the field of English language as their target language (Gürler, 2015; Sailan, ARG \& Normawati, 2017; Nadiah, 2019; Al-Hebaish, 2012). Various results have been confirmed as regards the correlation was high depending on the criteria scholars have determined to research. Exploiting the same target with the public speaking sector, Nadiah, Arina \& Ikhrom (2019) examined the correlation and came up with the result that the certainty about the students' level of confidence generated a great influence on their speaking performance in terms of verbal plus nonverbal performance. Earlier, researchers have identified a proportional correlation between the two mentioned variables (Park \& Lee, 2005; AlHebaish, 2012) that the higher the students' self-confidence achieved, the higher performance results they received. To reach this conclusion, they examined and analyzed various determinants of self-confidence in the manner of gender, verbal performance, nonverbal performance, or speaking scores. Acknowledging those studies, we notice that the determinants they analyzed are the consequences of the $\mathrm{ABC}$ sequence, which influence and affect human mindset and decision making. It is the basis that greatly contributes to one's level of self-confidence. Thus, in this study, we desire to gain insights 
into how students' self-confidence influences their English-speaking performance in terms of examining their level of affective, behavioral and cognitive segment of selfconfidence.

\section{Methods}

In this study, descriptive quantitative and qualitative methods were used. This research design figured out the relationships between self-confidence and English-speaking performance recurred by English-majored students at a university in Vietnam. Students were asked to complete surveys of two questionnaires (see in appendix A and B) that helped point out if they have self-confidence or not, and performance in speaking English. After that, we picked up 10 participants for the interview stage. Then data collected from the surveys and answers from the interviews were analyzed by using a tool named Statistical Package for the Social Sciences (SPSS). The results could indicate how students' self-confidence influenced their English-speaking performance.

\subsection{Participants}

The convenience sampling technique was applied to select 150 English-majored students at a private university Vietnam. Then a purposive sampling technique was used to select 10 students among 150 for interviews.

\subsection{Questionnaires}

To analyze students' self-confidence based on their behaviors while performing, we modified the PEI (Personal Evaluate Inventory) by Shrauger \& Schohn (1995), the Selfconfidence inventory by Geetha (2018), and the Speaking Strategies Questionnaire by Missoum (2014). In those instruments, we picked and then restructured some items that met our aims of measuring students' self-confidence based on the ABC Model (Ostrom, 1969). The rest of Part 1 were built from our study's theoretical framework, whose pilot's reliability results would be provided in section 3. A 5-Likert-scale was employed to analyze the students' self-confidence ranging from (1) Strongly Disagree to (5) Strongly Agree that participants could detect their level of self-confidence relying on their responses in the questionnaire.

We developed a second comprehensive questionnaire with 31 questions to assess students' self-confidence and English-speaking performance. We modified the Speaking Strategies Questionnaire developed by Missoum (2014), the IELTS Speaking Band Descriptors, and relied on the five components of content outlined by Lester (2011) to complete our questionnaire. We grouped the amended questions into eight categories which are pronunciation, grammar, vocabulary, fluency, comprehension, task, coherence, and content. This part also utilized a 5-Likert-scale with responses ranging from (1) Strongly Disagree to (5) Strongly Agree. 


\begin{tabular}{|l|l|}
\hline \multicolumn{2}{c}{ Table 1: Items of clusters used in the questionnaires } \\
\hline Clusters & Items \\
\hline 1. Affective Confidence & $1.1,1.2,1.3,1.4,1.5,1.6,1.7$ \\
\hline 2. Behavioral Confidence & $1.8,1.9,1.10,1.11,1.12$ \\
\hline 3. Cognitive Confidence & $1.13,1.14,1.15,1.16,1.17,1.18$ \\
\hline 4. Pronunciation & $2.1,2.2,2.3$ \\
\hline 5. Grammar & $2.4,2.5,2.6,2.7,2.8$ \\
\hline 6. Vocabulary & $2.9,2.10,2.11$ \\
\hline 7. Fluency & $2.12,2.13,2.14$ \\
\hline 8. Comprehension & $2.15,2.16,2.17,2.18$ \\
\hline 9. Task & $2.19,2.20,2.21,2.22$ \\
\hline 10. Coherence & $2.23,2.24,2.25,2.26$ \\
\hline 11. Content & $2.27,2.28,2.29,2.30,2.31$ \\
\hline
\end{tabular}

\subsection{Interviews}

The qualitative data were obtained through interviews with 10 students who had completed the questionnaires, of which five had highest and five had lowest results. All the questions used for the interview were made in both English and Vietnamese. Interview questions would be in Vietnamese or English depending on the participants' request so that they could understand and answer comprehensively. Researchers used Google Meet for online interviews and recorded the content directly on the app. If the interviewees chose Vietnamese, we would translate their answers into English. In addition, the content of the interview was completely recorded and carefully clarified to the participants before it was conducted. All of them were informed that their interview information was only used for research purposes and was kept confidential.

\subsection{Data collection procedures}

Data was collected within several steps. First of all, we first sent a participating invitation to classes that we intended to investigate. In the invitation email, we gave a brief explanation of our research to students, and attached the questionnaires' list that was already converted onto the Google Forms. Also, we mentioned the nature of our research and ensured that students' personal information will be secured and be used for this research purposes only. They were asked to complete the agreement of participating in this research, and they were also informed that there will be no penalty if they withdraw their participation from the research process. After their consent form's fulfillment, a questionnaire would be provided for our research purposes. The data collected was stored in Google Forms, then moved to Google Sheets so that we could interpret later. In addition, we then used a purposive sampling technique to choose 10 participants among the ones who answered our questionnaire before interviewing them via Google Meet. We used semi-structured interviews to collect qualitative data. 


\section{Results and Discussion}

\subsection{General statistical information the questionnaires and interviews}

As mentioned above, we used a convenience sampling technique to choose participants, and there were 150 participants from English-major classes involved. Then a purposive sampling technique was used to choose 10 participants among 150 participants in the survey, of which five participants have the highest mean scores of self-confidence and English-speaking performance, and five participants have the mean lowest scores.

In the questionnaires, the Cronbach's Alpha of all items reached .943, and two main variables are self-confidence and speaking performance attaining .865 and .934 respectively, which reached high level of reliability (see in Table 2).

Table 2: Cronbach's Alpha

\begin{tabular}{|l|c|c|}
\hline & Cronbach's Alpha & N of Items \\
\hline Self-confidence & .865 & 18 \\
\hline Speaking performance & .934 & 31 \\
\hline All items & .943 & 49 \\
\hline
\end{tabular}

The analysis results of all items had the mean result of 3.22 which was just above the average of 3.0. In addition, the mean index of self-confidence and speaking performance were 2.88 and 3.35 respectively (see in Table 3 ).

Table 3: Mean index

\begin{tabular}{|l|c|c|c|c|}
\hline & $\mathbf{N}$ & Minimum & Maximum & Mean \\
\hline Self-confidence & 150 & 1.06 & 4.59 & 2.8869 \\
\hline Speaking Performance & 150 & 1.49 & 4.78 & 3.3521 \\
\hline All items & 150 & 1.37 & 4.72 & 3.2252 \\
\hline
\end{tabular}

\subsection{Results from questionnaires}

In this section, the components of each cluster pair in SC and SP were thoroughly explained. Theoretically, the closer Pearson correlation approaches to 1, the greater the correlation value. In this survey, there were 24 pairs with significant correlations (see in Appendix A). It can be seen that Pearson correlations does indeed have a positive correlation (from $.244^{* *}$ to $.678^{* *}$ ); whenever a component from SC rises in value, so does its associated component from SP, and vice versa. Out of the 24 pairs, there are eight pairs with significant consideration, of which four have the highest correlation and four have the lowest correlation (see in Table 4 and Table 5). The correlations of each pair will be described below. 


\begin{tabular}{l}
\hline \multicolumn{1}{|c|}{ Table 4: The correlations of 4 pairs with highest points } \\
\begin{tabular}{|l|c|c|c|}
\hline Self-confidence & Speaking performance & Sig. (2-tailed) & Pearson correlation \\
\hline Cognitive Confidence & Vocabulary & .000 & $.613^{* *}$ \\
\hline Cognitive Confidence & Comprehension & .000 & $.614^{* *}$ \\
\hline Cognitive Confidence & Task & .000 & $.678^{* *}$ \\
\hline Cognitive Confidence & Coherence & .000 & $.636^{* *}$ \\
\hline
\end{tabular}
\end{tabular}

The four highest correlation index pairs were cognitive confidence and task $\left(.678^{* *}\right)$, cognitive confidence and coherence $\left(.636^{* *}\right)$, cognitive confidence and comprehension $\left(.614^{* *}\right)$, and cognitive confidence and vocabulary $\left(.613^{* *}\right)$. Bloom's cognitive hierarchy is used in our cognitive confidence questionnaire. It illustrates when cognitive confidence rises, so do the variables in SP increase, and vice versa. The cognitive confidence and task pair have the highest index $\left(.678^{* *}\right)$ among some of the highest pairings, suggesting that the more confident the speaker is in his or her knowledge, the greater the task completion rate.

Table 5: The correlations of 4 pairs with lowest points

\begin{tabular}{|l|c|c|c|}
\hline Self-confidence & Speaking performance & Sig. (2-tailed) & Pearson correlation \\
\hline Affective Confidence & Vocabulary & .000 & $.286^{* *}$ \\
\hline Affective Confidence & Coherence & .003 & $.244^{* *}$ \\
\hline Behavioral Confidence & Vocabulary & .001 & $.267^{* *}$ \\
\hline Behavioral Confidence & Coherence & .000 & $.285^{* *}$ \\
\hline
\end{tabular}

Affective confidence and coherence $\left(.244^{* *}\right)$, behavioral confidence and vocabulary pairings $\left(.267^{* *}\right)$, behavioral and coherence groups $\left(.285^{* *}\right)$, and affective confidence and vocabulary $\left(.286^{* *}\right)$ are the four pairs with weak correlations. The pair of affective confidence and coherence has the least value $\left(.244^{* *}\right)$ which shows that the lower the affective confidence, the weaker the coherence, and vice versa.

\subsection{Results from interviews}

Analyzing students' information from the interviews has also contributed to deeply understanding their thoughts of self-confidence in English speaking performance. Regarding affective self-confidence, the majority of participants said that it affected their English-speaking performance (whether high or low confidence), except for Student (S)2 and Student (S)4. There are many reasons why participants feel insecure when speaking: afraid to communicate $(\mathrm{S7}, \mathrm{S8}, \mathrm{S} 9, \mathrm{S10})$, afraid of making mistakes $(\mathrm{S} 3, \mathrm{S6})$ are examples. As S9 said:

"I have few opportunities to practice in class. I spend most of my time studying other majors... Another reason is being afraid to communicate with others."

Next, all interviewees said that behavior and gestures will reflect the level of confidence when performing English. S1, S2, S4, S5 said their behaviors when speaking 
English is completely confident, while S3 (belong to a high self-confidence group) said that S3 will still have an unconfident expression if he/she falls into an unexpected situation. The other group (S6, S7, S8, S9, S10) stated that when performing English, their voices will tremble, they stutter, and cannot control their gestures. The last factor, cognitive self-confidence, was agreed upon by most of the participants in terms of its influence on English-speaking performance, with the exception of S4. S4 believed that having confidence is a speaking skill that will make a better English-speaking performance.

The present study is to clarify the relationships between self-confidence and their speaking performance, hence, we have also explored our interviewees' perception on speaking performance's components. From the semi-structured interview's data, we found out that among the eight components of speaking performance, six out of eight are confirmed to have a certain level of influence on speaking performance except Coherence and Grammar. Most of the participants agreed that it is struggling to reach a certain comprehensive level when being hindered by some outer factors such as the questioners speak too fast (S7) or tricky questions (S1, S2, S6, S8), and some inner factors such as knowledge (S1, S2, S6) or impatience (S10). Mentioned about ensuring content of the speech, all of the interviewees except S4 and S10 supported to do information classification toward aimed audience before presenting something since it is related to the way to convey their points to the audiences. With questions about vocabulary, despite their self-confidence level, the interviewees have made less certainty as they evaluated it as just enough for information distribution (S1, S5, S8, S9) and even lack of words for speaking (S6, S7, S10). Otherwise, to guarantee a completed task, most interviewees practice speaking a lot before running on a presentation except S7 since he/she always completed his/her speech before the allowed time. With this question, S2 mentioned the effects of group work to his/her ability of time management as an unexpected factor:

"When giving a personal presentation, I have complete control over the timing. When giving group presentations, there are many other factors, I cannot guarantee completion within the allotted time."

From interviewees' sharing, most of them cannot maintain their fluency due to the lack of field knowledge (S3, S6, S7, S8, S9, S10) whereas the other four students (S1, S2, S4, S5) can go on their speech with made-up information or their existed knowledge. S5's opinion of when being in such a situation that she/he does not have much knowledge of a certain matter, as S5 said:

"Fluency will be limited when the topic is not well understood, but the content conveyed can still be partly guaranteed.". 
It is apparent from the interviewees' pronunciation self-evaluation that the higher self-confidence they are, the more confident they are towards their pronunciation, specifically S4 with his/her absolute confidence in pronunciation. Unexpectedly, two components Grammar and Coherence were not touched upon as influential components to the interviewees' speaking performance although the correlation between the two and self-confidence is nevertheless significant.

During the interview process, we realized that the channels (online presentations or face-to-face presentations) will affect the level of participants' confidence. According to S1, S3, S6, they believe that presenting in a face-to-face class will make them more confident through eye contact or body language. Besides, S2, S8, S9, S10 think that giving online presentations will give them higher confidence. S2 mentioned:

"I personally think that online presentations are not pressured by the audience's gaze because I can feel comfortable when I'm not directly standing in front of many people".

\subsection{Discussion and implications}

Since our study was to determine the relationship between students' self-confidence and their speaking performance, here we discussed our four findings.

The first finding, based on interview and survey results, suggests that there is an element of affective confidence, which is motivation, that does not participate in influencing the outcome of speaking English. As mentioned in Chapter 2, Krashen (2003) stated that affective confidence (AC) has three sub-factors: motivation, anxiety, and selfconfidence. All three of these sub-factors influence the process and outcome of SLA. Theoretically, when AC and speaking performance were positively related, each of the AC sub-factors would also have a similar correlation with speaking performance. The results of the survey and interview showed that only AC's anxiety and self-confidence were correlated with speaking performance, while motivation was not. We found that students' English-speaking performance did not improve whether they received encouragement from others or from themselves. It means that the outcome of speaking English well or not is not related to motivation, both internal and external, which is inconsistent with Krashen's theory of factors affecting the process and outcome of SLA. This implies that language learners need to realize the importance of improving their confidence and reducing their anxiety in order to achieve high English-speaking performance. Similarly, in the efforts of improving students' English-speaking performance, the faculty can provide curriculums that focus on two main tasks of enhancing students' confidence and eliminating students' anxiety while speaking English.

The second finding is that the repetition of behavior should be combined with one's cognition. According to Skinner (1957), language acquisition was accomplished by responding to stimuli when it becomes habitual; however, it could be claimed that behavior would become more meaningful and effective when it combined with intrinsic 
cognition as Chomsky (2013) pointed out. In our study, the relationships between behavioral confidence (BC) and English-speaking performance had 2 pairs with significant consideration, of which BC with comprehension, and BC with vocabulary. This result was in line with the studies of Chomsky (2013) and Johnson (2004). They claimed that behavior, including language learning, depended on organisms' intrinsic cognition rather than behavioral reinforcement, and therefore that they continuously adapt their behavior based on changing environments or circumstances. It is implied that learners can enhance themselves by developing a daily schedule for the strategic goals, adjusting and progressing through each specific goal. Furthermore, lecturers could base on accurate repetition of information or skills taught to students to provide explicit evaluation criteria as well as reliable feedback. Likewise, curricular frameworks can be considered as extra subjects that focus on speaking English and have a defined teaching approach to specific skills such as presenting and public speaking. Thus, students would be able to confidently express their ideas in English.

The third finding is that students' cognitive stages based on Bloom's taxonomy revised (1956) when performing their speech are fluctuated and disordered, which is slightly different from what was firmly established in studying cognitive processes (Bloom et al., 1956; Anderson et al., 2001). As it was previously studied, both Bloom's taxonomy original version (1956) and Anderson et al.'s revised version (2001) navigated learners to a fixed order of cognitive development, from lower-order to higher-order objectives, which are remember, understand, apply, analyze, evaluate, and create (Anderson et al., 2001). However, when stepping into the survey, we realized that the students' cognitive process did not follow an ascending development, instead, it was chaotic and fluctuated from preparation steps to the end of their speech. The new order in this study is create, apply, evaluate, remember, analyze, and understand. It means the students although have a certain knowledge of a matter, when presenting it to others, they otherwise struggle with some language difficulties, such as tough fields or topical uncertainty, that causes a descending self-confidence during the speech. This disorder happened similarly to other components of the students' speaking performance that the statistics did not increase hierarchically from the bottom to the top. From what has been analyzed, it can be concluded that when a student reaches a certain level of cognitive development in terms of Bloom's taxonomy, his/her level of cognitive confidence is unchanged throughout the speech, and it can be changed only when their knowledge is widened. Hence, it implies that in the attempt of enhancing field knowledge, language lecturers could provide various types of related knowledge for their students, as well as some subjects needed for widening the students' field knowledge extensively in the curriculums. Likewise, the students themselves need to be aware of the importance of field knowledge, which can be solidified by reading and learning diverse sources of information, towards their speaking performance. Furthermore, the syllabus provided for students needs to be designed by spending spaces for their own cognitive developments' enhancement. Since sometimes they can result in misused solutions or 
skip questions everwhen facing problems, by instructing them to perceive the importance of cognitive confidence, the students would have more chances to learn how to think on their own and therefore developing their cognition hierarchically as the Bloom's taxonomy.

Our final finding is drawn from the results of the interview that confidence in speaking English depends on the form of English presentation. The results of our interview obtained an additional factor which is the form of presentation. Individual presentation and group presentation both affect the self-confidence of interviewees, which in turn affects their speaking performance. As a result, most of the participants in the high self-confidence group chose the personal presentation format that provided them a higher confidence. They think that they can control everything when giving individual presentations and not being influenced by others as in group presentations. In contrast, participants with low self-confidence are more comfortable giving group presentations because they will receive support from their teammates when speaking or giving presentations in English. This implies that teachers can adapt their teaching methods to accommodate both high and low-confidence students. For students who choose to give group presentations, the lecturer can find a suitable teaching method, which helps to improve and enhance the students' confidence. At the same time, teachers should encourage and facilitate those students to give individual presentations so that they can build confidence when speaking English alone. Students who choose to give individual presentations need to be encouraged to participate in group presentations so that they know how to deal with unexpected situations and can be more confident in any situation. "Working in group" content should be integrated into the curriculum so that students in both groups can work effectively, which also helps students improve their self-confidence.

\section{Recommendations}

We suggest that further research should be done into the level of confidence of English learners, as well as recommendations for how to enhance their confidence and speaking performance. Further research might be conducted widely in other universities or in a similar context. To guarantee that new components with an external impact on learners' speaking confidence are discovered. That would be to say, future research is expected to provide a more realistic approach for boosting learners' confidence in their Englishspeaking performance.

\section{Conclusion and Implications}

During our discussion of the study's findings, we have come up with a number of ways to heighten English-majored students' self-confidence which are confirmed to have significant relationships with English speaking performance. The students involved in 
our study revealed that the proportional relationship is true, however, the most significant influence towards the performance is proven to be cognitive confidence. Reasonably, the more confident the students are with their language ability, the more they show a tendency of giving any speech individually. We have stressed some pedagogical suggestions in TESOL. During classes, instructions and encouragement of teachers/lecturers are indispensable for the students' self-confidence improvement. As a whole, it is essential to combine all of the $\mathrm{AC}, \mathrm{BC}$, and $\mathrm{CC}$ into instructions that a comprehensive development could be built efficiently. Moreover, curriculum developers should pay more attention to speaking and presentation skills, as well as field knowledge fulfillment classes in the attempt of building and enhancing self-confidence of Vietnamese university students in speaking English.

\section{Acknowledgements}

Our acknowledgements are given to all participants and colleagues who provided us with valuable support and feedback.

\section{About the Authors}

Anh Tuan Pham is currently working as an English lecturer at FPT University, Vietnam. His research interests include professional and educational development, EFL/ESL teaching methodologies, cultural and intercultural studies, psycholinguistic and sociolinguistic methodologies, and ICT in education.

Hieu Trung Hong; Tien Thuy Chau; Nhi Vo Anh Le; Phuc Thuy Thy Tran; My Ngoc Nhat Nguyen are undergraduate students at FPT University, Vietnam, under the supervision of Mr. Anh Tuan Pham. Their research interests are psycholinguistics of language education, teaching methodologies, and learning strategies.

\section{References}

Al-Hebaish, S. M. (2012). The correlation between general self-confidence and academic achievement in the oral presentation course. https://doi.org/10.4304/tpls.2.1.60-65

Anderson, L. W. (Ed.), Krahwohl, D. R. (Ed.), Airasian, P. W., Cruikshank, K. A., Mayer, R. E., Pintrich, P. W., Raths, J., \& Wittrock, M. C. (2001). A taxonomy for learning, teaching, and assessing: A revision of Bloom's taxonomy of educational objectives. Longman.

Andrews, M. C., \& Itsiopoulos, C. (2016). Room for improvement in nutrition knowledge and dietary intake of male football (soccer) players in Australia. International journal of sport nutrition and exercise metabolism, 26(1), 55-64. https://doi.org/10.1123/ijsnem.2015-0064

Arifin, W. L. (2017). Psychological problems and challenge in EFL speaking classroom. Register Journal, 10(1), 29-47. https://doi.org/10.18326/rgt.v10i1.29-47 
Arnold, J. (1999). Affect in language learning. Cambridge University Press.

Axelrod, R. H. (2017). Leadership and self-confidence. Leadership Today, 297-313. https://doi.org/10.1007/978-3-319-31036-7 17

Bandura, A. (1986). Social foundations of thought and action: A social cognitive theory. Prentice-Hall, Inc.

Bandura, A. (2001). Social cognitive theory: An agentic perspective. Annual review of psychology, 52(1), 1-26.

Berger, I. E. (1992). The nature of attitude accessibility and attitude confidence: A triangulated experiment. Journal of Consumer Psychology, 1(2), 103-123. https://doi.org/10.1016/s1057-7408(08)80052-6

Bloom, B. S., Engelhart, M. D., Furst, E. J., Hill, W. H., \& Krathwohl, D. R. (1956). Handbook I: cognitive domain. David McKay.

Brown, H. D. (2004). Language assessment: Principles and classroom practices. San Francisco State

University. https://www.academia.edu/26575645/H Douglas Brown Language Assessment Principles and Classroom Practice

Chomsky, N. (2013). A Review of BF Skinner's verbal behavior (pp. 48-64). Harvard University Press. https://doi.org/10.4159/harvard.9780674594623.c6

Eagly, A. H., \& Chaiken, S. (1998). Attitude structure and function. D. T Gilbert, S. T. Fiske, $\mathcal{E}$ G. Lindsay (Eds.), Handbook of social psychology, 2, 269-322. Boston: McGraw-Hill

Erin, L. R. (2013, May 26). The ABC model of attitudes: Affect, behavior E cognition [Video]. Study.com Lesson. https://study.com/academy/lesson/the-abc-model-ofattitudes-affect-behavior-cognition.html.

Geetha, S. (2018). A Survey of Self-confidence of B.Ed Students. http://ijepr.org/panels/admin/papers/434ij10.pdf?fbclid=IwAR35y4CswsA Rayj3 atZSHK8vLzKhDqSyNH44hTYkt1MGRahUG7wzZj9c

Gürler, I. (2015). Correlation between self-confidence and speaking skill of English language teaching and English language and literature preparatory students. Curr Res Soc Sci, 1(2), 14-19.

Harris, D. P. (1974). Testing English as a second language. McGraw Hill.

Hill, N. (1928). The law of success in 16 lessons. The Ralston University Press Meriden Conn. http://ia700209.us.archive.org/18/items/Law Of Success in 16 Lessons/law-ofsuccess-napoleon-hill text.pdf1109.

IELTS SPEAKING: Band Descriptors. https://www.ielts.org/-/media/pdfs/speaking-banddescriptors.ashx?la=en

Johnson, R. B., \& Onwuegbuzie, A. J. (2004). Mixed methods research: A research paradigm whose time has come. Educational researcher, 33(7), 14-26. 10.3102/0013189x033007014

Krashen, S. (2003). Principles and Practice Second Language Acquisition. Heinemann. 
Anh Tuan Pham, Hieu Trung Hong, Tien Thuy Chau, Nhi Vo Anh Le, Phuc Thuy Thy Tran, My Ngoc Nhat Nguyen THE RELATIONSHIPS BETWEEN STUDENTS' SELF-CONFIDENCE AND THEIR ENGLISH-SPEAKING PERFORMANCE: A CASE STUDY OF ENGLISH-MAJORED STUDENTS AT A PRIVATE UNIVERSITY IN VIETNAM

Lester, M. C. (2011, August 23). What is content? The World Factory. https://thewordfactory.com/what-is-content/?fbclid=IwAR0U0exrDjIj1ChaifsZ6DLcaS6H-wRoj7A2BEZq3kGuq BzOcDnY7XmW4

McLeod, S. A. (2016, February 05). Bandura - social learning theory. Simply Psychology. https://www.simplypsychology.org/bandura.html

McLeod, S. A. (2018, June 06). Jean Piaget's theory of cognitive development. Simply Psychology. https://www.simplypsychology.org/piaget.html

Missoum, M. (2014). Speaking Strategies Questionnaire. http://doi.org/10.13140/RG.2.2.27800.85763

Morozova, Y. (2013). Methods of Enhancing Speaking Skills of Elementary Level Students, 1-24. https://www.translationjournal.net/journal/63learning.htm

Nadiah, Arina, \& Ikhrom. (2019). The students' self-confidence in public speaking. Elite Journal, 1(1), 1-12. http://www.elitejournal.org/index.php/ELITE/article/view/7

Oney, E., \& Oksuzoglu-Guven, G. (2015). Confidence: A critical review of the literature and an alternative perspective for general and specific self-confidence. Psychological reports, 116(1), 149-163. https://doi.org/10.2466/07.PR0.116k14w0

Ostrom, T. M. (1969). The relationship between the affective, behavioral, and cognitive components of attitude. Journal of Experimental Social Psychology, 5(1), 12-30. https://doi.org/10.1016/0022-1031(69)90003-1

Park, H., \& Lee, A. R. (2005). L2 learners' anxiety, self-confidence and oral performance. Proceedings of the 10th Conference of Pan-Pacific Association of Applied Linguistics, 197208. PAAL Japan. http://paaljapan.org/resources/proceedings/PAAL10/pdfs/hyesook.pdf

Piaget, J. (1952). The origins of intelligence in children (M. Cook, Trans.). W W Norton \& Co. https://doi.org/10.1037/11494-000

Sailan, Z., Arg, Y. A. Y., \& Normawati, N. (2017). The correlation between motivation and self-confidence on students' speaking performance at Islamic religion education study program faculty of Tarbiyah IAIN Kendari. ELT-Lectura, 4(1). https://doi.org/10.31849/elt-lectura.v4i1.484

Shrauger, J. S., \& Schohn, M. (1995). Self-confidence in college students: Conceptualization, measurement, and behavioral implications. Assessment, 2(3), 255-278. https://doi.org/10.1177/1073191195002003006

Skinner, B. F. (1957). Verbal behavior. Appleton-Century-Crofts. https://doi.org/10.1037/11256-000

Skinner, B. F. (2019). The behavior of organisms: An experimental analysis. BF Skinner Foundation.

Tuan, L. T. (2012). Teaching and assessing speaking performance through analytic scoring approach. TPLS Theory and Practice in Language Studies, 2(4). https://doi.org/10.4304/tpls.2.4.673-679

Tuan, N. H., \& Mai, T. N. (2015). Factors affecting students' speaking performance at Le Thanh Hien high school. Asian journal of educational research, 3(2), 8-23. 
Anh Tuan Pham, Hieu Trung Hong, Tien Thuy Chau, Nhi Vo Anh Le, Phuc Thuy Thy Tran, My Ngoc Nhat Nguyen THE RELATIONSHIPS BETWEEN STUDENTS' SELF-CONFIDENCE AND THEIR ENGLISH-SPEAKING

PERFORMANCE: A CASE STUDY OF ENGLISH-MAJORED STUDENTS

AT A PRIVATE UNIVERSITY IN VIETNAM

\begin{tabular}{llllll}
\hline Watson, J. & B. (1998). Behaviorism & (1st & ed.).
\end{tabular}

https://doi.org/10.4324/9781351314329

Creative Commons licensing terms

Author(s) will retain the copyright of their published articles agreeing that a Creative Commons Attribution 4.0 International License (CC BY 4.0) terms will be applied to their work. Under the terms of this license, no permission is required from the author(s) or publisher for members of the community to copy, distribute, transmit or adapt the article content, providing a proper, prominent and unambiguous attribution to the authors in a manner that makes clear that the materials are being reused under permission of a Creative Commons License. Views, opinions and conclusions expressed in this research article are views, opinions and conclusions of the author(s). Open Access Publishing Group and European Journal of Education Studies shall not be responsible or answerable for any loss, damage or liability caused in relation to/arising out of conflicts of interest, copyright violations and inappropriate or inaccurate use of any kind content related or integrated into the research work. All the published works are meeting the Open Access Publishing requirements and can be freely accessed, shared, modified, distributed and used in educational, commercial and non-commercial purposes under a Creative Commons Attribution 4.0 International License (CC BY 4.0). 